\title{
A STUDY ON THE RESTRICTING MAINTENANCE MANAGEMENT PRACTICES ON PUBLIC INFRASTRUCTURE: EVIDENCE FROM GHAHA
}

\author{
Agyemang Fredua Sylvester Prempeh ${ }^{1 *}$, Minkah Andrews Yaw ${ }^{1}$, \\ Emmanuel Bosompem Boadi',
}

\author{
${ }^{1}$ School of Management, Jiangsu University, Zhenjiang 212013, P.R. China. \\ ${ }^{2}$ School of Public Administration, Hohai University, Nanjing 202001, P.R. China.
}

Corresponding Author: Agyemang Fredua Sylvester Prempeh ${ }^{1^{*}}$

Article DOI: https://doi.org/10.36713/epra9632

DOI No: $10.36713 /$ epra9632

\begin{abstract}
The research aim is to assess the restricting maintenance management practice in Ghana mainly focusing on Kumasi Sports stadium. Specifically, how restricting maintenance practices such as, absence of maintenance policy (AMP); ignoring maintenance responsibility (IMR) and Poor Infrastructure design (PID) affect public facilities in Ghana. A Self-administered questionnaire was used to collect primary data after a pilot test. The data were described using frequency distribution and percentages. The results from multiple regression analysis indicated that there is a positive significant linear relationship between Restricting Maintenance Management Practices and Public Infrastructure in Ghana due to the fact that Restricting Maintenance Practices affects the betterment of the stadia leading it to deteriorate. The study recommends there should be a maintenance policy that compels stakeholders to be accountable for ignoring maintenance responsibility
\end{abstract}

KEYWORDS: Public Infrastructure, stadium, Facility Maintenance Management, Restricting Maintenance Practice

\section{INTRODUCTION}

Public Infrastructure accounts for a large portion of every nation's asset which is controlled by the government for public consumption. It can be divided into 3 categories, machinery and equipment, buildings and engineering structures. They consist of roads, ports, entertainment facilities and stadia. Ghana's development is constrained by huge infrastructure deficits. The infrastructure deficit will require continued expenditure of US $\$ 2.3$ billion per year over a decade to close the gap (Ghana News Agency, 2017). In 2008, when Ghana decided to host the African Cup of Nations, the inspection team of the International Football Federation (FIFA) which praised and lauded Ghanaians for prompt facelift of the stadia that were selected for the tournament, also criticized the awful nature of the same stadia a decade after.

In Ghana, particularly in some regions, restricting maintenance management practices have resulted in a loss of investment value for these sports facilities. Some of these infrastructure have shown serious dilapidation. The research generally emphases on restricting maintenance practices of public infrastructure, especially Kumasi Stadium. The research therefore seeks to look into the Restricting factors of Maintenance Practices (Absence of Maintenance Policy, Ignoring Maintenance Responsibility, and Poor Infrastructure Design) that leads to deplorable nature of the Kumasi Sport stadium.

This study is crucial because it does not only contribute to knowledge and theory, but will also contribute to the good maintenance practices of Ghanaian public infrastructures. Moreover, the results derived from this study will create awareness for stadia managers, maintenance managers, equipment officer and largely for national sports council on activity that can minimize poor maintenance. 


\section{EPRA International Journal of Research and Development (IJRD)}

\section{LITERATURE REVIEW}

\section{Absence of Maintenance Policies on Public Infrastructure} (Stadia)

Presently, there seem no maintenance policies which control maintenance of public utilities presently in Ghana. Nevertheless, there is existence of estate workshop department that work in accordance with the infrastructure management committee that industrialized maintenance for many public infrastructures. However, these strategies frown upon anticipatory maintenance (Quayson and Akomah 2016). Not paying attention to activities such as painting etc. will lead to the main problematic that hints utilities to demolition. There are no rules and regulations which induce stakeholders to commence maintenance failure to be punished (Cobbinah PJ, 2010).

Jusoff et al (2008) also noted that poor management practices are prevalent due to the lack of detailed management guides for most institutions to govern the manner of facility management services and identified facility management in Malaysia as ' not having consistent practice and implementation mechanism. They found that poor management practices in Malaysia can be traced to the nonexistence of a regulatory facility management association that regulates the practice of property management consultants in Malaysia. The findings are similar to Ghana, but there are disciplines in Ghana with well-established associations governing their activities, and their services and products are still performing below expectation. These agencies lack a clear maintenance policy.Thus, the study hypothesized that,

H1. There's direct effect of absence of maintenance policies on public infrastructure (stadia)

\section{Ignoring Maintenance Responsibilities on Public Infrastructure (Stadia)}

Apathy and ignorance of maintenance responsibility on the part of facility managers plays a major part in the current maintenance problems of public infrastructure facilities. Management refuses to undertake internal maintenance as directed by the maintenance guidelines of the various institutions. Many leaders lack maintenance culture, idea, desire and compassion (Omotehinshe et al., 2015b) that are some of the leadership traits essential to impact and excite people's behavior gears to preserving and supporting prevailing facilities. Facility managers sometimes consider building new infrastructures than maintaining old ones. (Sam, Brijs et al. 2018). There's not much attention given to repairs which will generate to greater damage. A research conducted by Jusoff et al (2008) in Malaysia brought to the fore that poor facility can be linked to low priority placed by an institution on facility management. The absence of ready local expertise to attend to the poor state of repairs is considered as a main purpose for poor facility management. The study hypothesized that,

H2. There's direct effect of ignoring maintenance responsibility on public infrastructure (stadia)

\section{Poor Infrastructure Design and Construction on Public Infrastructures (Stadia)}

A building's location has influenced on maintaining an infrastructure. The location relates to the building's precise loci. So, location is affected by environmental topography, soil type and salty water, as well as elevated temperatures and severe variations in temperature. In areas with high moisture, most materials hold enough moisture that can affects during the infrastructure in drought area, some fabrics might also weakening to achieve the purpose it was built up for sake of hydration. The parts of infrastructure, which are likely to be damaged, are the wooden structures, the roofs, particularly the corrugated iron sheets (S. Afranie and Osei Tutu, E 1999).

Waziri (2016) believed that poor infrastructure design and construction exposes infrastructures to extreme unexpected maintenance needs that contribute significantly to poor facilities in various public infrastructures. Similarly, previous studies by Adejimi (2005) and Chohan et al (2011) also showed that appalling condition of public infrastructure may be due to the incapability of construction experts to combine maintenance and management of facilities at the design and construction level of a life cycle of buildings. Such shortcomings in the design stage are also mostly followed by poor buildings resulting in a regular deterioration of facilities during post-occupancy surveys (Adejimi, 2005). Thus, it is hypothesized that,

H3. There is direct influence of poor building design and construction on public infrastructure (stadia).

\section{METHOD}

Kumasi Sports Stadium is a multi-function stadium located in the capital of Ashanti region Kumasi, of Ghana. It is the biggest stadium in Ghana, having about 40,528 seating capacity. The Kumasi Stadium is mainly assigned for soccer games, though it can also use for athletics. It is home to Asante Kotoko, one of the most well-known sports club in Africa. The stadium was initially constructed in 1957 and inaugurated in 1959 as a preferred soccer pitch. The first stands were built in 1971. The stadium was reconstructed in 1977. It was retitled after Kumasi-born footballer Baba Yara (1936-1969, active for Asante Kotoko 1955-1961) under the New Patriotic government in 2004. The third significant works were completed in 2008. The western stand was ruined as part of the work to be exchanged by a bilateral stand with press, corporate and VIP facilities. The remaining stands have been upgraded, seats have been added, and transparent panels have been connected to distinct the spectator zone from the playing area to avoid assaults of the pitch (Onodugo, Ugwuonah, \& Ebinne, 2010).

The total population for the research consists of all employees, facility managers and top managers. In view of this, purposive sampling technique was employed to recruit the various respondents of the research. Total of (400) participants were involved for the survey. The collected data was analyzed using multiple regression models via SPSS tool 


\section{EPRA International Journal of Research and Development (IJRD)}

version 25. Multiple regression analysis enabled hypotheses $\mathrm{H} 1, \mathrm{H} 2$ and $\mathrm{H} 3$ to be tested. The multiple regression model RESULTS AND FINDINGS used for this study is mathematically written as follows:

$$
Y=\beta_{0}+\beta_{1} X_{1}+\beta_{2} X_{2}+\beta_{3} X_{3}+\mu
$$

Table 1: Respondents' Social Profiles

\begin{tabular}{|c|c|c|c|}
\hline Variables & Characteristics & Frequency & Percentage \\
\hline Gender & Male & 282 & 70.5 \\
& Female & 118 & 29.5 \\
\hline Age & $18-35$ & 134 & 33.5 \\
& $36-45$ & 202 & 50.5 \\
& $46-59$ & 34 & 8.5 \\
& 60 and above & 30 & 7.5 \\
\hline Marital Status & Married & 86 & 43.0 \\
& Single & 114 & 57.0 \\
\hline Years of Employment & $1-5$ & 72 & 18.0 \\
& $6-10$ & 168 & 42.0 \\
& $11-20$ & 100 & 25.0 \\
& 20 and above & 60 & 15.0 \\
\hline
\end{tabular}

\section{Reliability Test Analysis}

In general, Cronbach alpha value over 0.7 indicates a good reliability of questionnaire (Babin et al 2006). Thus, a questionnaire was administered as data collection instruments for Sports stadia in Ghana to access the maintenance management practices. As shown in the table below, the total estimated value of Cronbach's Alpha is 0.905. This clear indication of high reliability and consistency as far as the data collection is concerned. Also, the findings show that the questionnaire administered as a tool for data collection is reliable and hence suitable for the objectives of this current study.

Table 2. Results of Cronbach's Alpha

\begin{tabular}{ccc}
\hline Cronbach's Alpha & $\begin{array}{c}\text { Cronbach's Alpha Based on } \\
\text { Standardized Items }\end{array}$ & Number of Items \\
\hline 0.905 & 0.911 & 11 \\
\hline
\end{tabular}

Source; Field Survey

Factor Analysis

Table 3. Results of KMO and Bartlett's Test

\begin{tabular}{|c|c|}
\hline KMO Measure of Sampling Adequacy & 0.852 \\
\hline & 6752.142 \\
\hline & 577 \\
\hline & $0.000 * * *$ \\
\hline
\end{tabular}

\section{Source; Field Survey}

From the outcome, an estimated value of 0.852 was realized. This implies that the factor analysis is appropriate to analyze the attributes or features. Similarly, Bartlett's test of sphericity is strongly significant with a P-value of 0.000 . Thus, indicating that it is suitable for further analysis.

\section{Correlation Matrix}

It shows a positive relationship between the dependent variable, mediating variable and the independent variables. The presented variables are Absence of Maintenance Policy, Ignoring Maintenance Responsibility, Poor Building Design and Public infrastructure (stadia) denoted by AMP, IMR, PID and PI respectively.

Table 4. Correlations

\begin{tabular}{llllll}
\hline \hline & & PI & AMP & IMR & PID \\
\hline \multirow{3}{*}{ Pearson Correlation } & PI & 1.000 & & & \\
& AMP & .612 & 1.000 & 1.000 & .623 \\
& IMR & .744 & .577 & .824 & 1.000 \\
\hline \hline
\end{tabular}

Source: Field Survey. 


\section{SJIF Impact Factor 2022: 8.197| ISI I.F. Value:1.241| Journal DOI: 10.36713/epra2016 ISSN: 2455-7838(Online) EPRA International Journal of Research and Development (IJRD)}

The table above vividly reveals that PID displays a strong positive relationship with PI and also has a greater correlation coefficient roughly 0.81 with the dependent variable (PI). This implies that PID is among the powerful contributors to the poor outlook of public infrastructure (stadia). All the variables indicate a strong positive relationship with the dependent variable. What this means is that, both the independent variables and the mediator are all bottlenecks to the sustainability of the Public infrastructure (stadia) with their positive correlation coefficient figures above the threshold.

Basically, if there is a rise in any of the variables, there is the likelihood of further deplorable of public infrastructure (stadia). This implies, when stadia managers ignored their responsibilities to carry out maintenance needs the more the stadia facilities becomes useless.

\section{Regression Analysis}

Considering the prime motive of the study in mind, a multiple regression analysis was adopted to access the influence of the independent variables on the dependent variable. The results gained from the regression model help to explain the causal relationships between the various variables. There are three independent variables and a dependent variable in this current study.

Table 5. Coefficient

\begin{tabular}{|c|c|c|c|c|c|c|}
\hline \multirow{2}{*}{\multicolumn{2}{|c|}{ Model }} & \multicolumn{2}{|c|}{$\begin{array}{l}\text { Unstandardized } \\
\text { Coefficients }\end{array}$} & \multirow{2}{*}{$\begin{array}{r}\begin{array}{c}\text { Standardized } \\
\text { Coefficients }\end{array} \\
\text { Beta }\end{array}$} & \multirow[t]{2}{*}{$\mathbf{T}$} & \multirow[t]{2}{*}{ Sig. } \\
\hline & & B & Std. Error & & & \\
\hline \multirow{4}{*}{1} & (Constant) & .264 & .118 & & 2.236 & .026 \\
\hline & AMP & .294 & .104 & .846 & 2.826 & .000 \\
\hline & IMR & .174 & .053 & .166 & 3.271 & .000 \\
\hline & PID & .140 & .029 & .133 & 4.819 & .000 \\
\hline
\end{tabular}

\section{a. Dependent Variable: PI}

Source: Field Survey

This result is highly significant with a P-value of .000 . AMP, IMR and PBD P-values are highly significant with .000, 0.00 and .000 respectively displaying a positive relationship with the dependent variable. Their positive relationship implies that they contribute highly to poor outlook of Public infrastructure (stadia) and which is increased by $0.294,0.174$ and 0.140 with an additional unit of AMP, IMR and PBD respectively.

The outcomes shown that hypotheses, H1, H2 and H3 can be accepted as the result revealed positive relationship between them and the dependent variable with strong significant values.

\section{FINDINGS}

These results confirm the study hypothesis (H1) that Absence of Maintenance Policy has a positive and significant impact on public infrastructure. Jusoff et al (2008) opined that, the deplorable conditions of Public infrastructure are prevalent due to the lack of detailed management guides. The researchers also established that in practice, every wellmaintain public infrastructure seems to be governed by a detailed maintenance policy and found that there was none in Malaysia for infrastructure management. However, there are workshop departments and other agencies that developed maintenance procedures but they do not pay much attention to preventive maintenance (Quayson and Akomah 2016).

The study revealed that, poor infrastructure maintenance outlook of the stadia is linked to ignoring maintenance responsibilities. Waziri (2016) surprisingly reported that poor supervision during and after the construction of the public facilities is due to the poor state of public infrastructure. According to Peter (2016), Facility managers ignore their basic responsibilities to restore official facilities until such assets are at danger of endangering users' lives.

Waziri (2016) believed that poor infrastructure design and construction exposes Infrastructures to extreme unexpected maintenance needs that contribute significantly to poor facilities in various public infrastructures. More often than not, poor building designs are accompanied by poor construction and the use of inappropriate materials for the construction of these infrastructures (Jusoff et al., 2008).

\section{CONCLUSION AND IMPLICATION}

Certainly, Public infrastructures, Stadia to be precise are very useful and contribute to the wellbeing of every society. Investing heavily in infrastructure provision has been a major achievement of government and has attracted interest from the general public. However, its maintenance to serve the purpose it is built for has been heavily scrutinized by several scholars. The findings reveal that, restricting maintenance management practices affects the betterment of the designated Sports Stadia. However, this study recommends implementation of maintenance policy that compels mangers that ignored their respective responsibilities to be punished and also abreast good maintenance practices. The research is important as it has provided a suitable precedence for other studies to follow for improvement in research on implementation. A study which collects data from all Sports Stadia in Ghana will enable the generalization of the results. In addition, a comparative study can be performed by including causes of 


\section{SJIF Impact Factor 2022: 8.197| ISI I.F. Value:1.241| Journal DOI: 10.36713/epra2016 ISSN: 2455-7838(Online) EPRA International Journal of Research and Development (IJRD)}

poor maintenance practice of public infrastructure outside Ghana. Also, further research is also needed into the role of the national sports council in the management of Stadia facilities.

\section{Conflicts of Interest}

The authors declare that they have no competing interests.

\section{REFERENCE}

1. Agbenorku, P. (2018). Evolution of burn injury management in KATH, Kumasi-Ghana, 1954-2017. Burns Open, 2(1), 59-65. https://doi.org/10.1016/j.burnso.2017.11.002

2. Akinyemi, A. P., Gambo, M. D., Ankeli, I. A., \& Dabara, I. D. (2016). Building collapse in Nigeria: Issues and Challenges. Conference of the International Journal of Arts and Sciences, 1st to 4th December 2015.

3. Bin Syed Mustapa, S. A. H., \& Jusoff, K. (2009). Facility management challenges and opportunities in the Malaysian property sector. Journal of Sustainable Development, 1(2), 79. https://doi.org/10.5539/jsd.v1n2p79

4. Bernoff $J, L i$ C. Groundswell: Winning in a world transformed by social technologies. Boston: Harvard Business School Publishing. 2008.

5. Campbell, J. D. \& Reyes-Picknell, J. V. (2006) Uptime: Strategies for Excellence in Maintenance.

6. Congressional Budget Office. (2014). Public Spending on Transportation and Water Infrastructure: 1956 to 2014.

7. De la Fuente, A., et al. (2018). Advanced Techniques for Assets Maintenance Management. IFAC-PapersOnLine, 51(11), 205-210.

https://doi.org/10.1016/j.ifacol.2018.08.260

8. Dugalic, S. (2013). Management of Activities in the Opening of Sporting Events through the Techniques of Network Planning. Sport Logia, 9 (2), (www.sportlogia.com)

9. David Kyei (2008-01-06). Kotoko to celebrate 50yrs of Kumasi Sports Stadium." Asante Kotoko. Archived from the original on 2008-01-15. Retrieved 2008-02-06.

10. Fuseini, I., et al. (2017). City profile: Tamale, Ghana. Cities, 60, 64-74.

https://doi.org/10.1016/j.cities.2016.07.010

11. Feng, X., \& Humphreys, B. (2018). Assessing the economic impact of sports facilities on residential property values: $A$ spatial hedonic approach. Journal of Sports Economics, 19, $188-210$

12. Florence, F.A., (2011). An Empirical Analysis of Asset Replacement Decisions and Maintenance Culture in Some Government Organizations Located in Ogbomoso and Ilorin Metropolis as Case Study. Journal of Management and Society, 1 (3), 01-09. Industrial Press Inc.

13. Guenzi, P. (2007) 'Sport marketing and facility management: from stadiums to customer-based multipurpose leisure centres', in Desbores, M. (Ed.): Marketing and Football an International Perspective, pp.130-162, Butterworth-Heinemann, Oxford.

14. Hyva ri, I. (2006). Project management effectiveness in project-oriented business organizations, International Journal of Project Management, 24(13), 216-225. https://doi.org/10.1016/j.ijproman.2005.09.001
15. Jusoff, K., Mustapa Syed, S. A. H. bin, \& Adnan, H. (2008) Facility Management Challenges and Opportunities in the Malaysian Property Sector. Journal of Sustainable Development, Vol. 1(No. 2), 79-85.

16. Joseph, M. (2014). An assessment of the contribution of Form Two National examination to academic performance in Form Four National examination: The case of Community Secondary Schools in Mara Region. The Open University of Tanzania.

17. Inhabitant (20 May 2009). Taiwan's solar stadium 100\% powered by the sun." The Guardian. Retrieved 2 September 2017.

18. Humphreys, B., \& Zhou, L. (2015). Sports facilities, agglomeration, and public subsidies. Regional Science and Urban Economics, 54, 60-73.

19. Joseph, M. (2014). An assessment of the contribution of Form Two National examination to academic performance in Form Four National examination: The case of Community Secondary Schools in Mara Region. The Open University of Tanzania.

20. Lavy, S., Garcia, J. A., \& Dixit, M. K. (2010). Establishment of KPIs for facilities performance measurement: a review of the literature, Facilities, 28(10), 440-464, 2010.

21. Lee, P.-C., et al. (2018). An integrated system framework of building information modeling and geographical information system for utility tunnel maintenance management. Tunneling and Underground Space Technology, 79, 263-273. https://doi.org/10.1016/j.tust.2018.05.010

22. Nkrumah, ENK. (2017) Public Infrastructure Maintenance Practices in Ghana. Review Pub Administration Management, (5), 234. Doi: 10.4172/2315-7844.1000234 www.ajaronline.com 3(3) (Pages 48-56) ISSN 2408-7920 (March 2016) 48 maintenance of residential buildings of selected public institutions in Ghana

23. Olayonwa, G. O. (2000). Property management: Principles and practice. Iwo: Debo Publishing Co.

24. Omotehinshe, O. J., Dabara, I. D. \& Guyimu, J. (2015a). Design Inadequacies and the Maintenance of University Buildings in Ile Ife, Nigeria. Journal of Environment and EarthScience.5(2),175-187.Availableonlineat http://iiste.org/Journals/index.php/JEES/article/view/19478

25. Oyedel, O. A. (2012). The Challenges of Infrastructure Development in Democratic Governance, Retrieved on February 17, 2014, from https://www.fig.net/pub/fig2012/papers/ts01c/TS01C_oyede le_6119.pd

26. Pierre-Richard, A., \& Moreno-Dodson, B. (2006). Public Infrastructure and Growth: New Channels and Policy Implications. Policy Research Working Paper 4064. The World Bank, WA

27. Propheter, G. (2018). Estimating the effect of sports facilities on local area commercial rents: Evidence from Brooklyn's Barclays Center. Journal of Sports Economics, (forthcoming).shington, $D C$.

28. Rosentraub, M. (2014). Reversing urban decline: Why and how sports, entertainment, and culture turn cities into major league winners. Routledge

29. Sam, E. F., et al. (2018). Public bus passenger safety evaluations in Ghana: A phenomenological constructivist exploration. Transportation Research Part F: Traffic 
Psychology and Behaviour, 58, 339-350. https://doi.org/10.1016/j.trf.2018.06.031

30. San, S. (2012). Determinant factors in the development of maintenance culture in managing public asset and facilities. Int Cong Interdisc Bus Soc Sci 65, 827-832. https://doi.org/10.1016/j.sbspro.2012.11.206

31. Seeley, I. H. (1987). Building maintenance. Nottingham: Macmillan Press Ltd, UK. https://doi.org/10.1007/978-1349-18925-0

32. Waziri, B. S. (2016) Design and Construction Defects Influencing Residential Building Maintenance in Nigeria. Jordan Journal of Civil Engineering, 10(3), 313-323.

33. Wuni, I. Y. (2016).Poor Property Management among Government institutions. An empirical study of Bawku Senior High School and Bawku Technical Institute, Munich, GRIN Verlag,

https://www.grin.com/document/340335 